\title{
Uniaxial Compressive Strength Variation for Multi-point Support Design and Discontinuity Mapping for Tunnel Stability Analyses and Stope Dilution Assessment
}

\author{
Kalume $\mathrm{H}^{1}$, Chileshe P R K ${ }^{2}$ \\ ${ }^{1}$ (Copperbelt University, School of Graduate Studies; Lubambe Copper Mine Ltd) \\ ${ }^{2}$ (Copperbelt University, School of Mines and Mineral Sciences, Kitwe, Zambia) \\ Corresponding Author: * Kalume H
}

\begin{abstract}
:
Introduction: A geotechnical study was undertaken at Lubambe Copper Mine, Zambia, centring on understanding the variations in the uniaxial compressive strength of all rock units coupled with underground discontinuity mapping. The current mining method employed at Lubambe is Longitudinal Room and Pillar (LRP) mining with $30 \mathrm{~m}$ strike-wide panels. The Lubambe Copper deposit is located within the Central African Lufilian arc fold and thrust belt. It is located in an area underlain largely by rocks belonging to the Katanga sequence group.

Problem: The mine has experienced a number of fall of ground incidents since its inception in 2011, which is against the company policy of zero tolerance. The fall of ground incidents were believed to be as a result of instability controlled by many factors including UCS and the overall jointing system. Significant dilution problems had been encountered in some stopes.

Objective: The main objective of the study was to conduct UCS testing and underground discontinuity mapping at Lubambe Copper Mine in order to predict implications of tunnel stability, slope dilution and support design.

Methodology: The study involved collection of samples of all rock units at Lubambe. Seventy (70) rock core samples $50 \mathrm{~mm}$ in diameter were prepared according to ASTM standard. The UCS was derived by uni-direction loading on the specimen with constant load increment until point of failure. In order to understand the geological structures that control tunnel stability, scan line discontinuity mapping was performed in already developed tunnels, which were plotted and analysed in Dips stereo-net commercial software.

Results and interpretation: A summary of variations on rock units was established. Estimation of other rock parameters was performed in RocLab software package. UCS results of all the main mine rock units indicated significant variation, which led to the suggestion of a multi-point support design approach where UCS values were part of numerical indices used for design. Frequently, numerical indices such as RMR and $Q$, are determined on a contribution from mean UCS, that is, a single point. The situation such as encountered at Lubambe suggests that a multipoint design approach should be adopted, right from the outset. The mapping conducted revealed an interaction of three prominent joint sets which were identified to be controlling the overall tunnel stability as well as stope dilution.
\end{abstract}

Keywords: Discontinuity Mapping, Joint sets, Stope Dilution, Support Design, Tunnel Stability, Uniaxial Compressive Strength (UCS)

Date of Submission: 22 -06-2017

Date of acceptance: 13-07-2017

\section{Introduction}

A geotechnical study was conducted at Lubambe Copper Mine to understand the variations in strength of different rock formations, and how this coupled with jointing to cause tunnel instability and stope dilution. The study involved analysing the strength parameters of various rock formations and underground discontinuity mapping in order to establish the major joint sets. Lubambe Copper Mine (LCM) has experienced a number of fall of ground incidents, which is against the company policy of zero tolerance on fall of ground incidents. Lubambe is located in Chililabombwe, Zambia, Figure 1, and is a joint copper mining venture with three partners that include African Rainbow Minerals (40\%), Vale (40\%) and the Government of Zambia (20\%) 


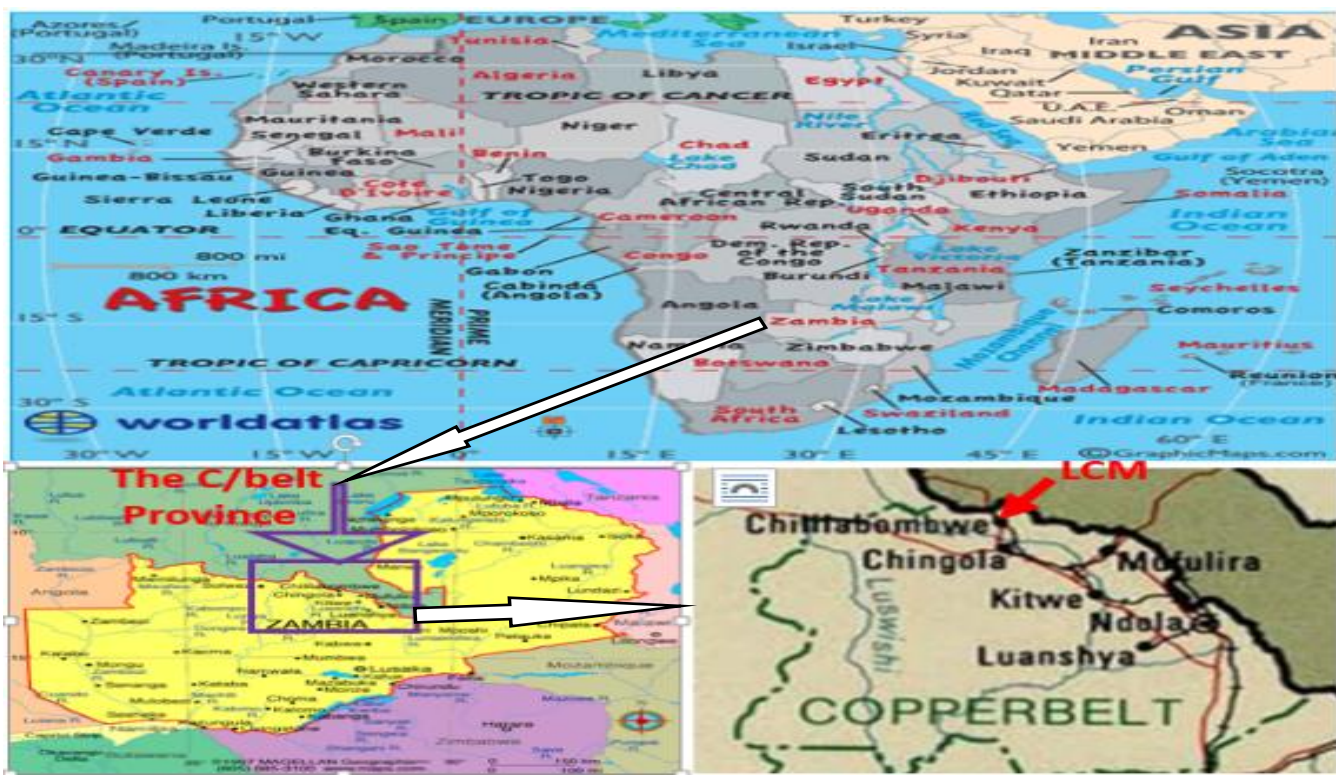

Figure1: Location of Lubambe Copper Mine

The current mining method utilises Longitudinal Room and Pillar Mining (LRP) on $30 \mathrm{~m}$ long panel strike length with $5 \mathrm{~m}$ rib pillars as shown in Figure 2. However, a separate study was conducted on optimisation of stope strike length and showed that $50 \mathrm{~m}$ panels on $5 \mathrm{~m}$ rib pillars are likely to be stable. Therefore certain panels at Lubambe are beyond the standard of $30 \mathrm{~m}$ but not exceeding $50 \mathrm{~m}$.

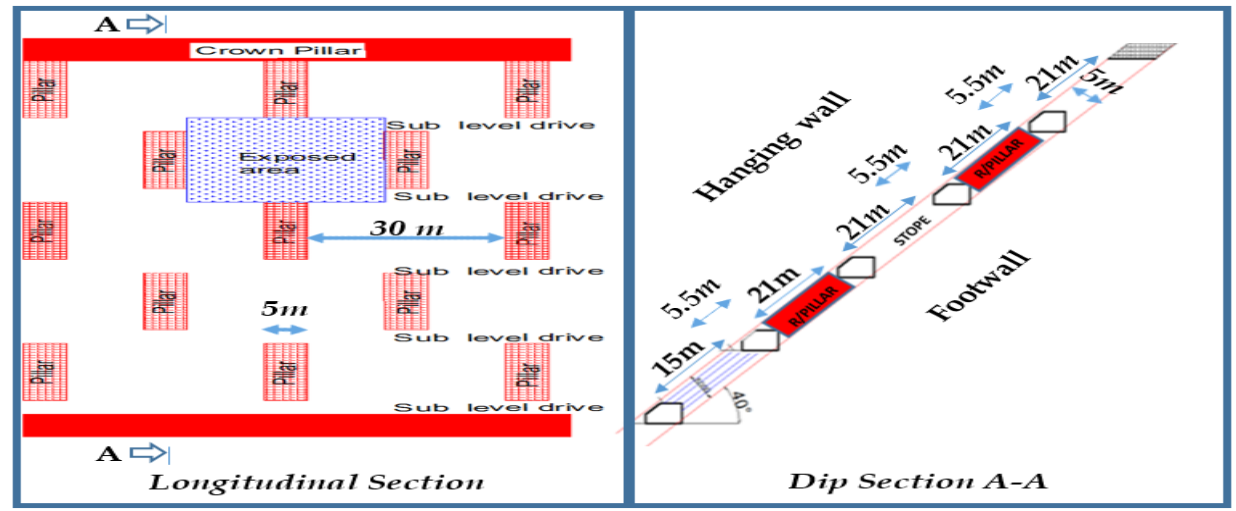

Figure 2: Longitudinal Room and Pillar Mining Layout

The study involved collection of samples of all rock units at Lubambe and subjecting them to uniaxial compressive testing, estimating rock properties using RocLab software package [1] and conducting underground discontinuity mapping in mined tunnels in order to understand the UCS and major jointing system influencing overall stability and stope dilution.

\section{Lubambe Copper Mine Stratigraphy}

The Lubambe Copper deposit is one of the major copper deposits occurring within the central African Copperbelt. It is located at the north-western extremity of the Zambian portion of the Copperbelt and represents an autochthonous "Zambian type" deposit within the late Lufilian arc fold and thrust belt. The property is located in an area underlain largely by rocks belonging to the Katanga sequence Roan group. This area is characterised by thick clastic sediments composed of predominantly arenaceous and argillaceous rocks with relatively thin interbeds of rudaceous material. Copper mineralisation is largely hosted with the Ore shale OS1 member of the Nchanga formation which is the first major reducing horizon above a $1000 \mathrm{~m}$ thick sequence of oxidised arkoses and conglomerates. Although copper mineralisation occurs mostly within the OS1 member, it is crosscutting on a gross scale and pinches out towards the east within the overlying OS2 member.

The Lubambe Copper Mine stratigraphy is defined on the basis of sequence stratigraphic approach as shown in Figure 3. 


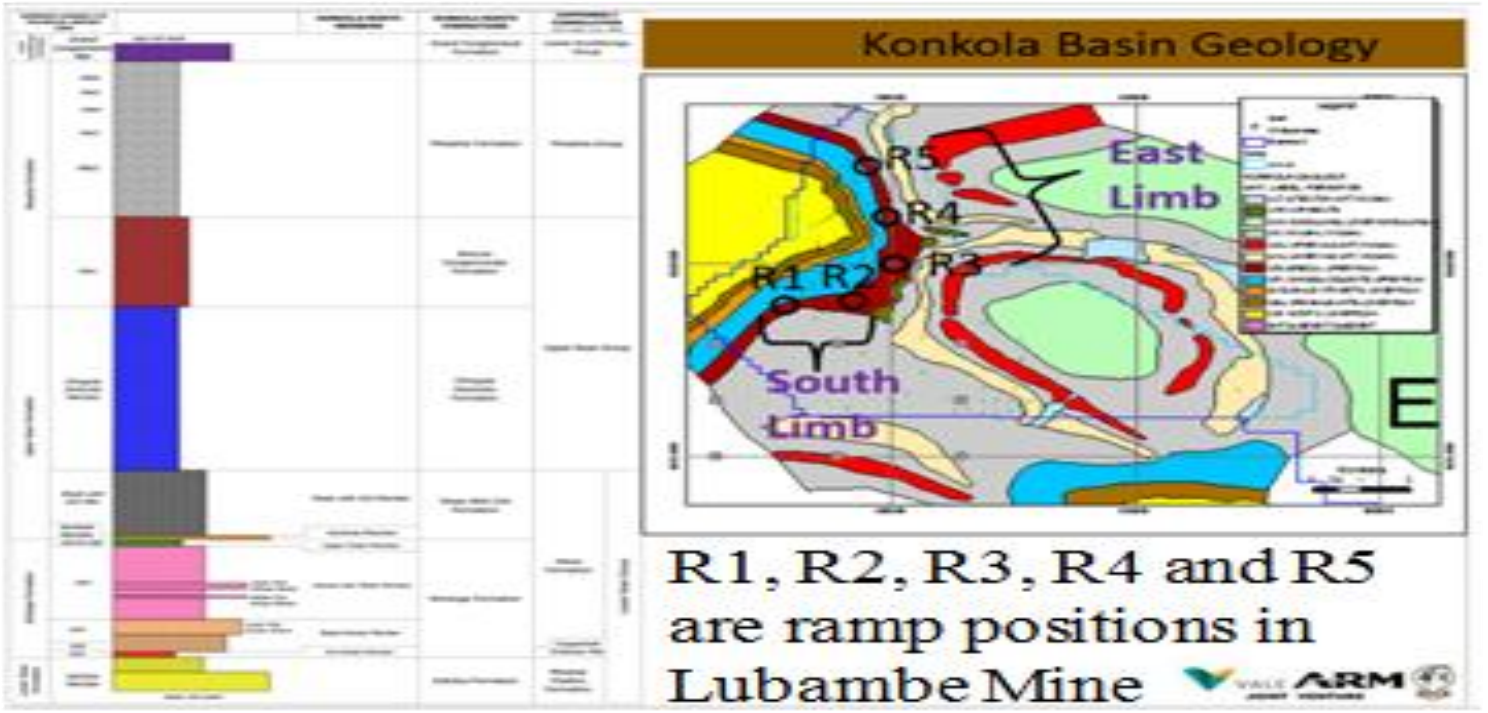

Figure 3: Lubambe Copper Mine Stratigraphic Column and Geological Plan

\section{Main Objective}

The main objective was to conduct UCS testing and underground discontinuity mapping at Lubambe Copper Mine, in order to predict implications for tunnel stability, stope dilution and support.

\subsection{Sub-Objectives}

- To investigate UCS variation of all rock units at Lubambe Copper Mine for support implications.

- To establish major joint sets contributing to the overall tunnel stability and stope dilution.

\section{Methodology}

The study involved UCS testing and discontinuity mapping as detailed below.

\subsection{Compressive strength testing}

Rock core samples $50 \mathrm{~mm}$ diameter were prepared according to ASTM standard. The samples used in the test were fresh cores from various geological units obtained through diamond drilling. Before conducting any test works, each sample was assessed for any imperfections such as presence of joints, vugs and cavities [2]. It was appreciated that this might introduce some bias towards stronger strength results. The rock type and degree of weathering was estimated in order to ensure that physical defects did not influence the outcome of the mechanical test performed, and also to ensure correct interpretation of the results. The uniaxial compressive strength test was performed by uni-direction of load on the specimen [3] as shown in Figure 4.

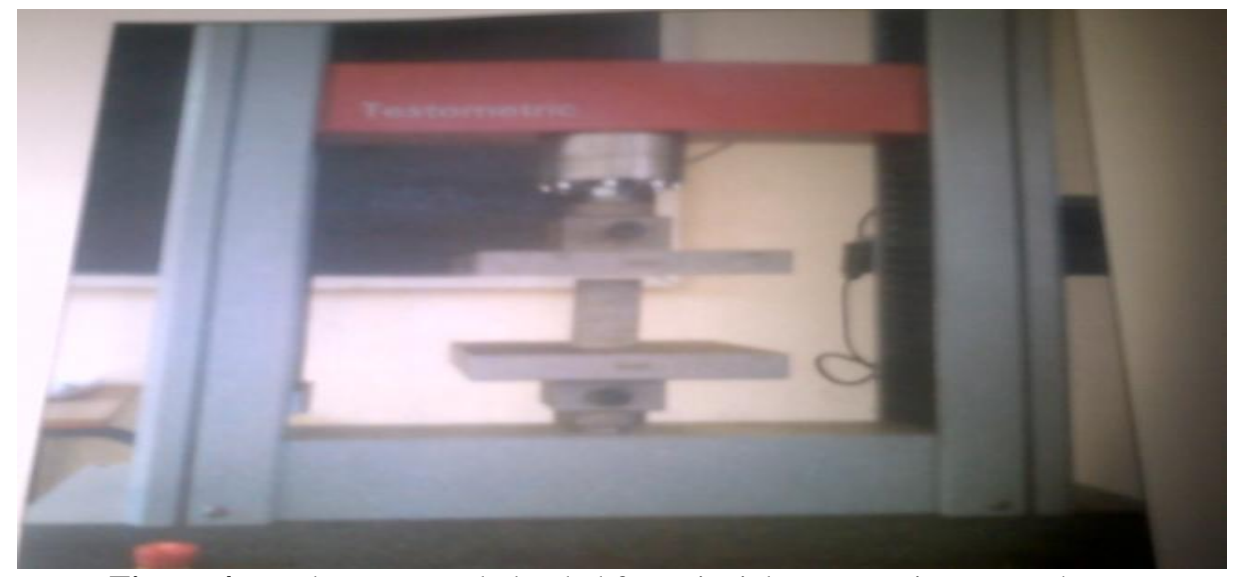

Figure 4: Rock core sample loaded for uniaxial compressive strength test

Constant load increment was performed until point of failure which was recorded. The stress-strain curves for all the geological units were plotted as shown in Figure 5. 

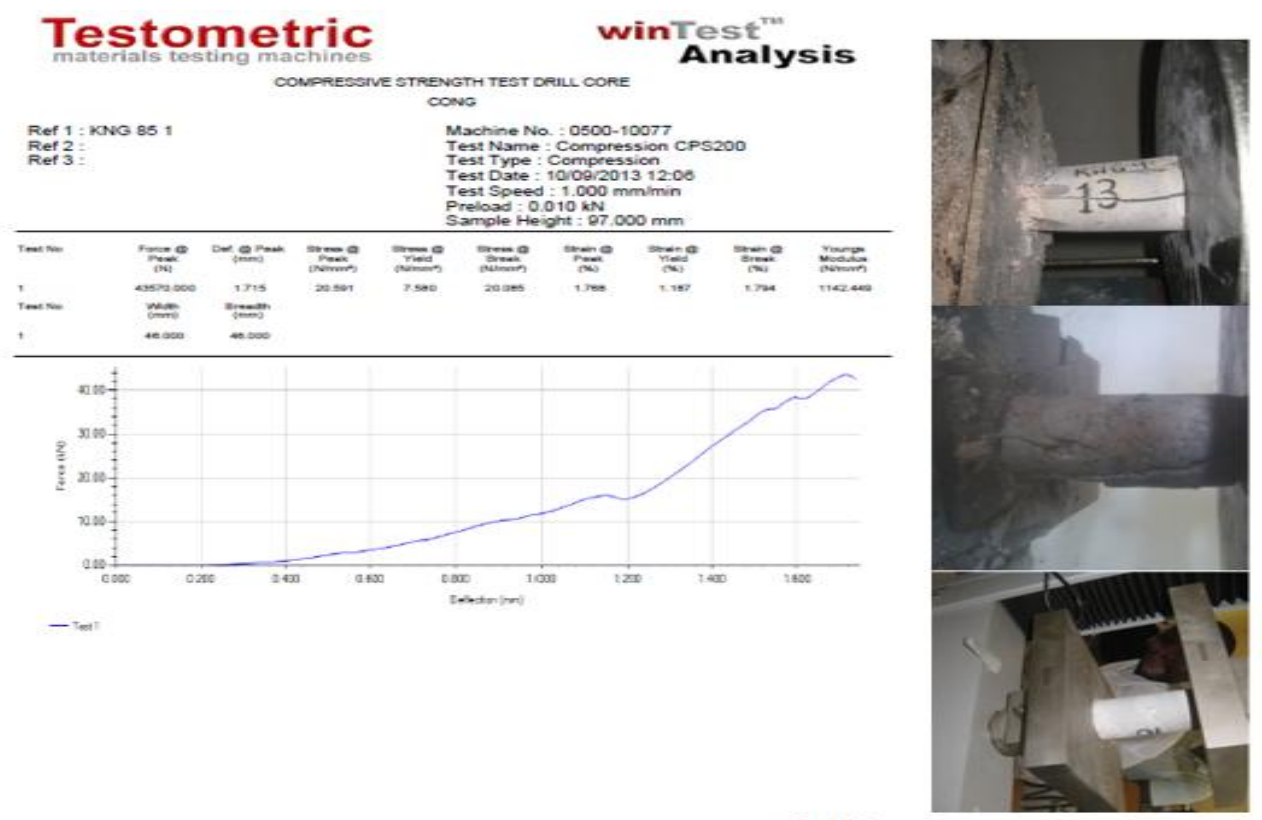

Page 1 oe 1

Figure 5: Stress-strain graph for Conglomerate

\subsection{Geotechnical underground discontinuity mapping}

In order to understand the geological structures that might control overall tunnel stability, scan line discontinuity mapping was conducted on already developed primary and secondary developments. Various geological features such as joints and faults [4] with their corresponding dip/ dip directions were mapped and recorded.

The various dip/ dip directions were plotted and analysed in DIPS software.

\subsection{Uniaxial compressive strength}

\section{Findings And Discussions}

\section{Orebody}

The OS1 is the formation forming the current orebody being exploited and hosts all the secondary developments. Seventeen (17) samples from OS1 were collected and uniaxial compressive tested. The strength values obtained ranged from as high as $60.1 \mathrm{MPa}$ to as low as 5.8 $\mathrm{MPa}$. The corresponding normal distribution graph of OS1 test results is as depicted in Figure 6 with $10.6 \mathrm{MPa}, 26.7 \mathrm{MPa}$ and $42.8 \mathrm{MPa}$ being one standard deviation below mean (33\%), mean and one standard deviation above mean (33\%) strengths, respectively.

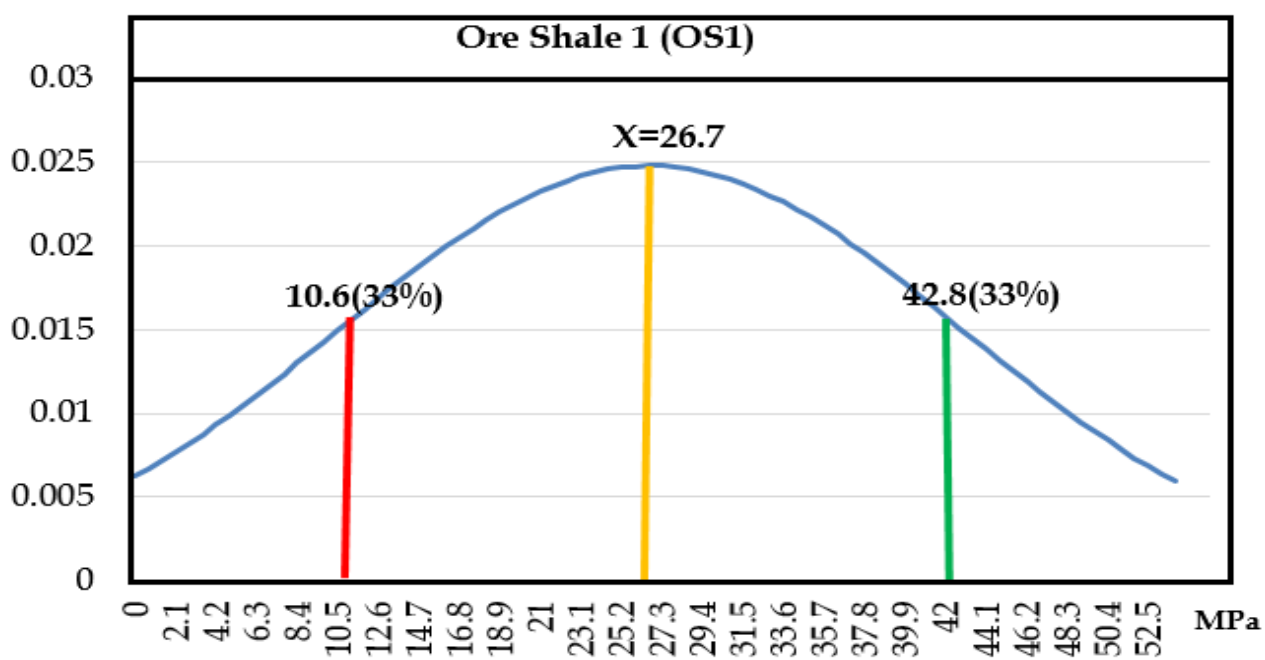

Figure 6: Uniaxial Compressive Strength of OS1on a normal distribution curve 
Uniaxial Compressive Strength Variation for Multi-point Support Design and Discontinuity..

\section{Hangingwall}

The OS2 forms the immediate formation on the hanging wall side. Twenty five samples of OS2 were collected and uniaxial compressive strength tested. A variation of strength results were obtained ranging from as low as 13.2 MPa to as high as 91.6 MPa. The corresponding normal distribution graph of OS2 is as shown in Figure 7 with 16.4 MPa, 36.2 MPa and 56 MPa being one standard deviation below mean (33\%), mean and one standard deviation above mean (33\%) strengths respectively.

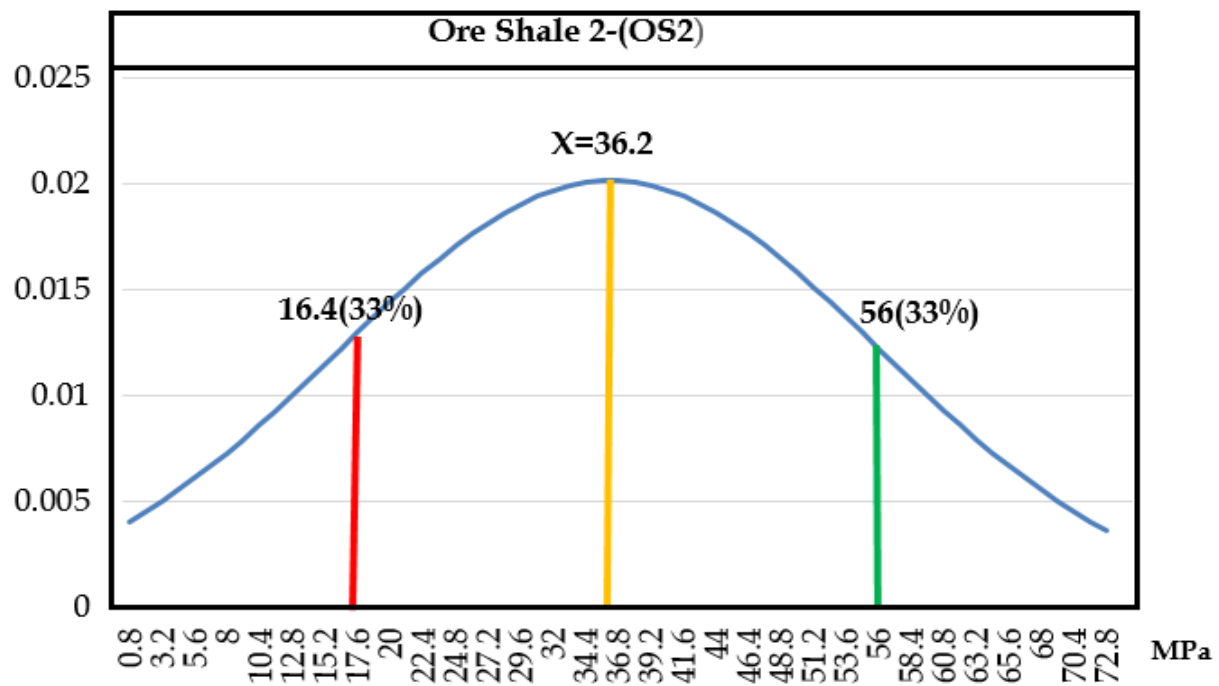

Figure 7: Uniaxial Compressive Strength of OS2 on a normal distribution curve

\section{Footwall}

The Conglomerate forms part of the footwall next to the Orebody. A total of twenty three samples were obtained and subjected to uniaxial compressive strength test. Various strength results were obtained ranging from 8.61 $\mathrm{MPa}$ to $94.7 \mathrm{MPa}$. The corresponding normal distribution graph of conglomerate is as shown in Figure 8 with 22.2 MPa, 46.9 MPa and 71.6 MPa being one standard deviation below mean (33\%), mean and one standard deviation above mean (33\%) strengths respectively.

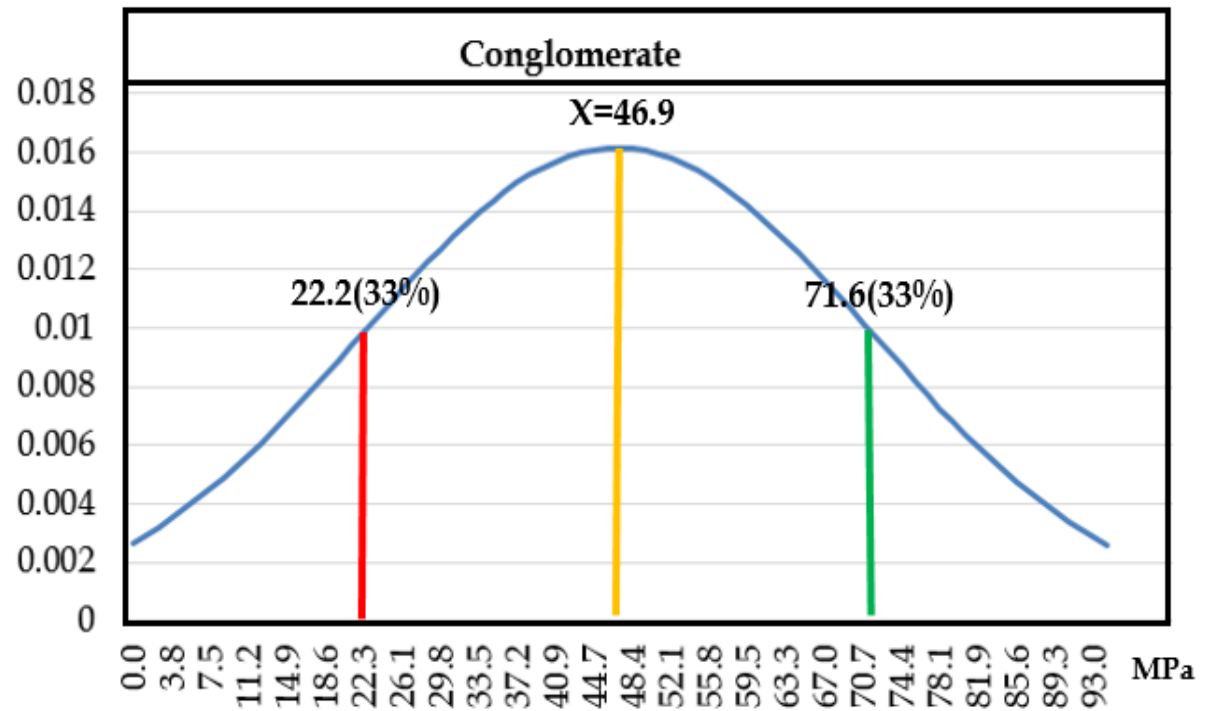

Figure 8: Uniaxial Compressive Strength of Conglomerate on a normal distribution curve

Arkose forms the main footwall and hosts all the primary developments. Seventeen samples collected in this formation produced various strength results ranging from 15.27 $\mathrm{MPa}$ to $105.26 \mathrm{MPa}$. The corresponding normal distribution graph of conglomerate is shown in Figure 9 with $34.6 \mathrm{MPa}, 55.6 \mathrm{MPa}$ and $76.6 \mathrm{MPa}$ being one standard deviation below mean (33\%), mean and one standard deviation above mean (33\%) strengths respectively. 


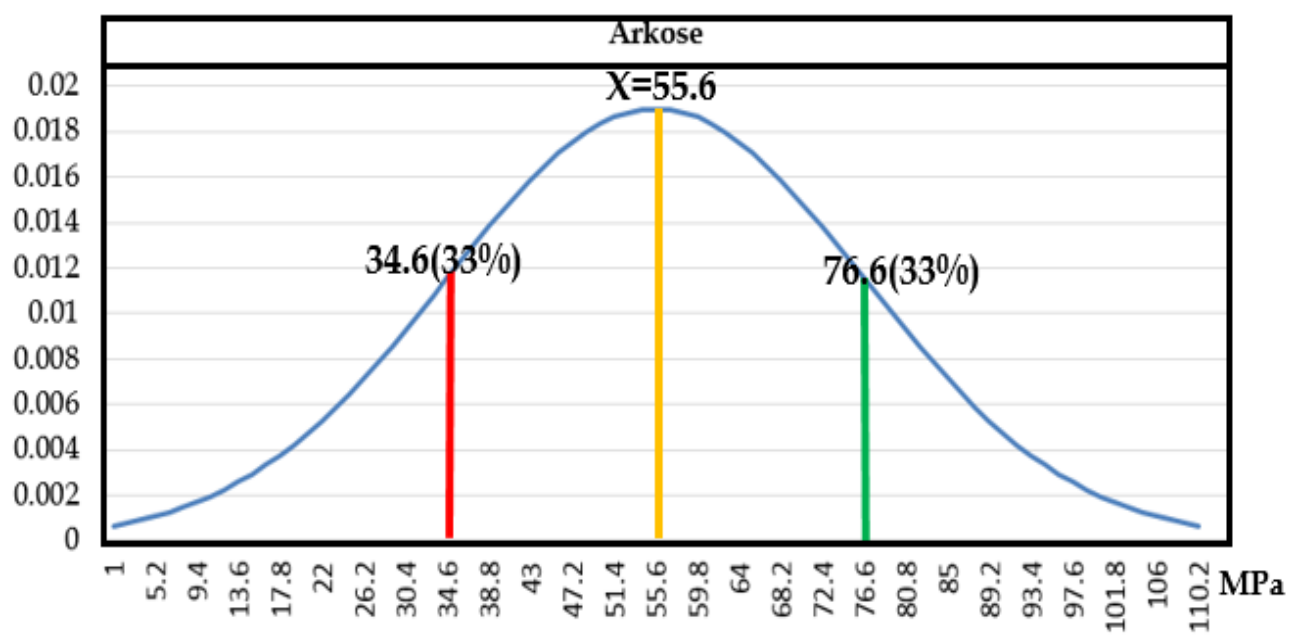

Figure 9: Uniaxial Compressive Strength of Arkose on a normal distribution curve

The mean uniaxial compressive strengths of statistically significant samples of all the rock units tested at Lubambe Copper Mine is as summarised in the histogram in Figure 10. It can be deduced that there is significant variation in strength of rock units at Lubambe. The highest mean strength was obtained in Arkose (55.65 MPa), conglomerate (46.06 MPa), OS2 (36.23 MPa) and OS1 (26.7 MPa) in the decreasing order.

The extreme variations in UCS indicate that in certain stress environments, weaker strata of the same lithology may experience strength related failures. This has been experienced in a number of areas developed within the OS1. Certain portions that are kaolinised tend to experience strength related failure while other areas within the same locality do not.

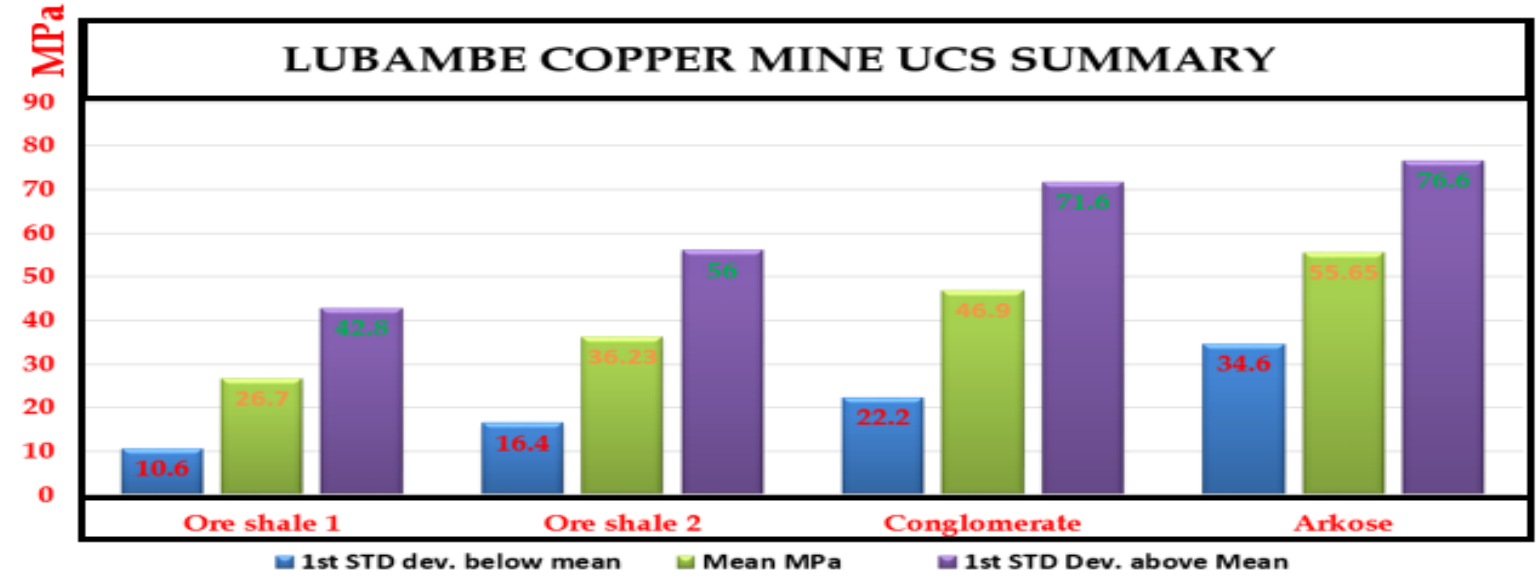

Figure 10: Summary of strength values on all rock units at Lubambe Copper Mine Zambia

\subsubsection{Support design implications of UCS variations}

Frequently, numerical indices such as Rockmass Rating (RMR) [5] and Rock Quality (Q) [6], are determined on, among others, a contribution from mean UCS, that is, a single point. The situation such as encountered at Lubambe suggests that a multipoint support design approach should be adopted, right from the outset. In this case, UCS values of one standard deviation below, the mean and one standard deviation were adopted, that is multiple points. Other points could be selected as preferred. A multi-point support design approach should be tried, that is, strata support should have three support designs, one pessimistic (one standard deviation below mean), normal (mean) and optimistic (one standard deviation above mean), which can then be correlated to unfolding events as mining progresses. Here, the variation is being applied to UCS, however, the variations of other parameters in RMR, for example, could be used, dependent on what is considered to be important. The mine can then build experience with time and subsequent development.

\subsection{Rockmass classification}

The main classification systems for rock support estimates the Q and RMR. For arriving at appropriate results in rock engineering and support design, Bieniawski (1989) advised at least two classifications when applying such empirical tools. The RMR and Q can be related in equation 1: 
Where:

$$
\mathrm{RMR}=9 \ln \mathrm{Q}+44 \quad \text {......... Eq. } 1
$$

RMR-Rockmass rating

Q-Rock quality system (Barton et al (1974)

Estimation of various RMR from Q-system for Lubambe is as depicted in Table 1.

Table 1: Relationship between Rock Quality System (Q) and Rockmass rating at Lubambe

\begin{tabular}{|c|c|c|c|c|c|c|c|}
\hline Rock Unit & $\mathbb{R Q D}$ & $\mathrm{Jn}$ & $\mathrm{Jr}$ & $\mathrm{Jw}$ & $\mathrm{SRF}$ & $\mathrm{Q}$-Value & $\mathrm{RMR}=9 \mathrm{ln} \mathrm{Q}+4 \mathrm{4}$ \\
\hline Arkose & 72 & 2 & 1.5 & 1 & 2.5 & 15.9 & 68.9 \\
\hline Conglomerate & 69 & 4 & 1.5 & 1 & 2.5 & 12.3 & 66.6 \\
\hline Ore Shale 1 & 49 & 8 & 1.5 & 1 & 2.5 & 6.2 & 60.4 \\
\hline Ore Shale 2 & 51 & 6 & 1.5 & 1 & 2.5 & 7.1 & 61.6
\end{tabular}

Different support regimes would be adopted according to the ground conditions exposed. Estimate of mean values on all the rock units was conducted using RocLab package and is as shown in Figure 11.

The modulus of deformation for the rockmass was estimated by using the equation of Serafim and Pereira [7], which was identified by Hoek and Diederichs [4] as appropriate for shallow mine depths such as at Lubambe, expressed as in equation 2 :

Where:

$$
\mathrm{E}_{\mathrm{m}}=10^{(\mathrm{RMR}-10) / 40} \quad(\mathrm{MPa}) \quad \ldots . . . . \mathrm{Eq} .2
$$

$$
\mathrm{E}_{\mathrm{m}}-\text { modulus of deformation }
$$

These values were further used as input parameters in the numerical modelling process, not shown in this paper.

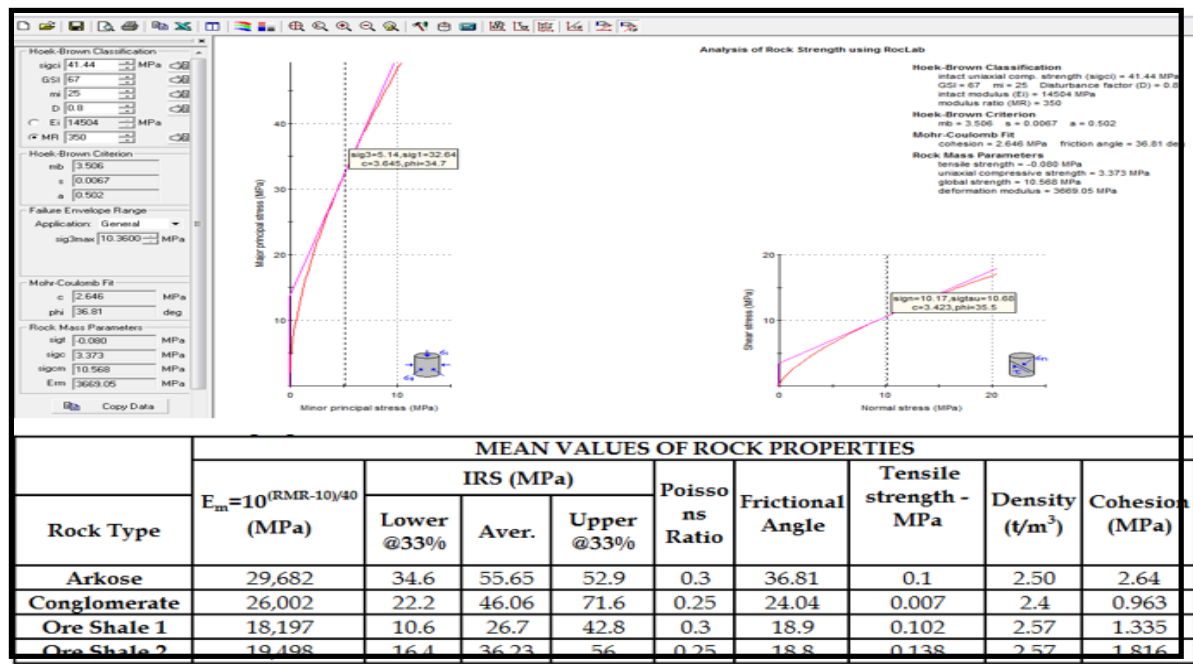

Figure 11: Derived rock material properties

\subsection{Kinematic feasibility}

Based on discontinuity mapping conducted on some of already developed tunnels at Lubambe, an interaction of three prominent jointing systems, namely, J1 (68/282), J2 (65/057) and J3 (84/126) exists as shown in Figure 12. This jointing system was identified to be controlling the overall tunnel stability. 


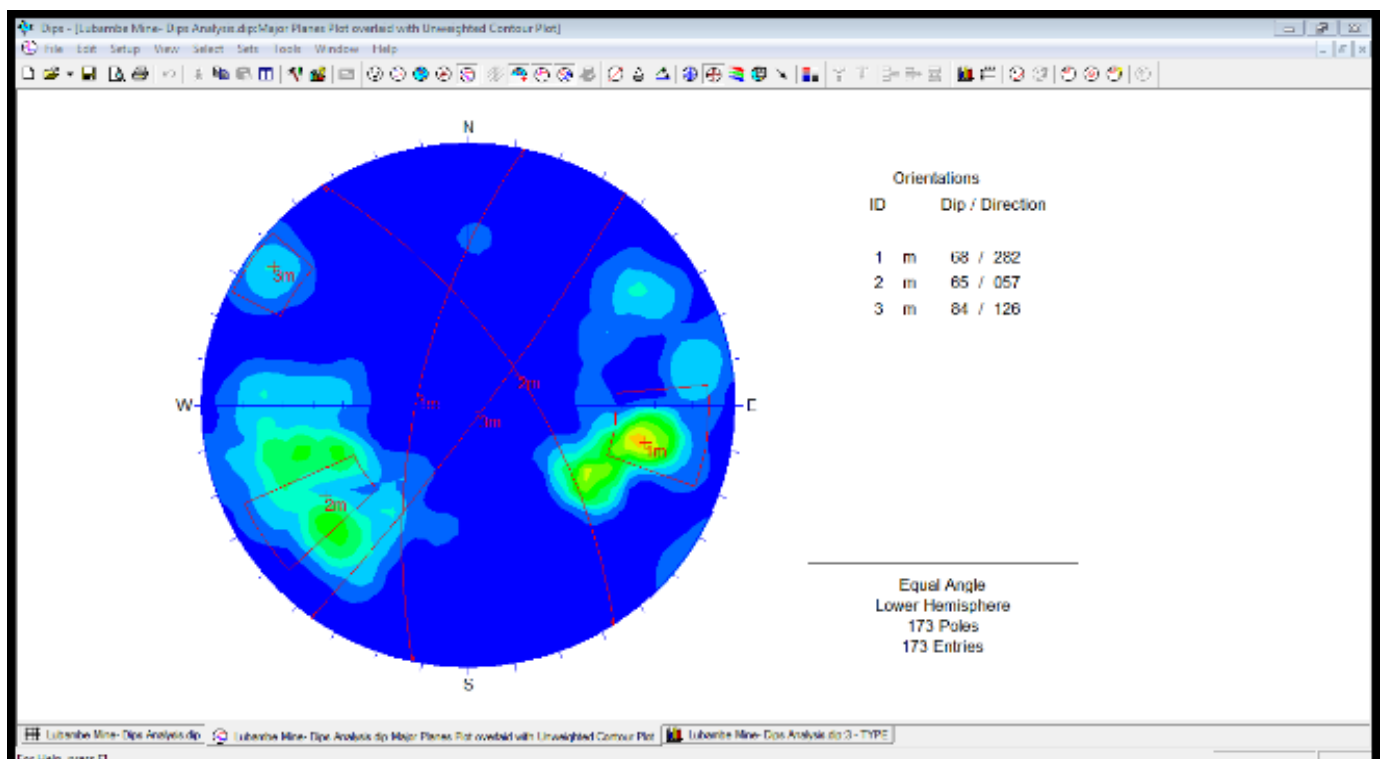

Figure 12: Analysis of Jointing System at Lubambe in Dips commercial software

Detailed analysis of the stereo-net plotting in Figure 12 suggests that more structurally controlled instability is likely to occur from vertical loading. Conducting a wedge analysis of the three major joint sets shows that maximum wedges of 16 tonnes are capable of forming from the hanging wall side on the East Limb as shown in Figure 13.

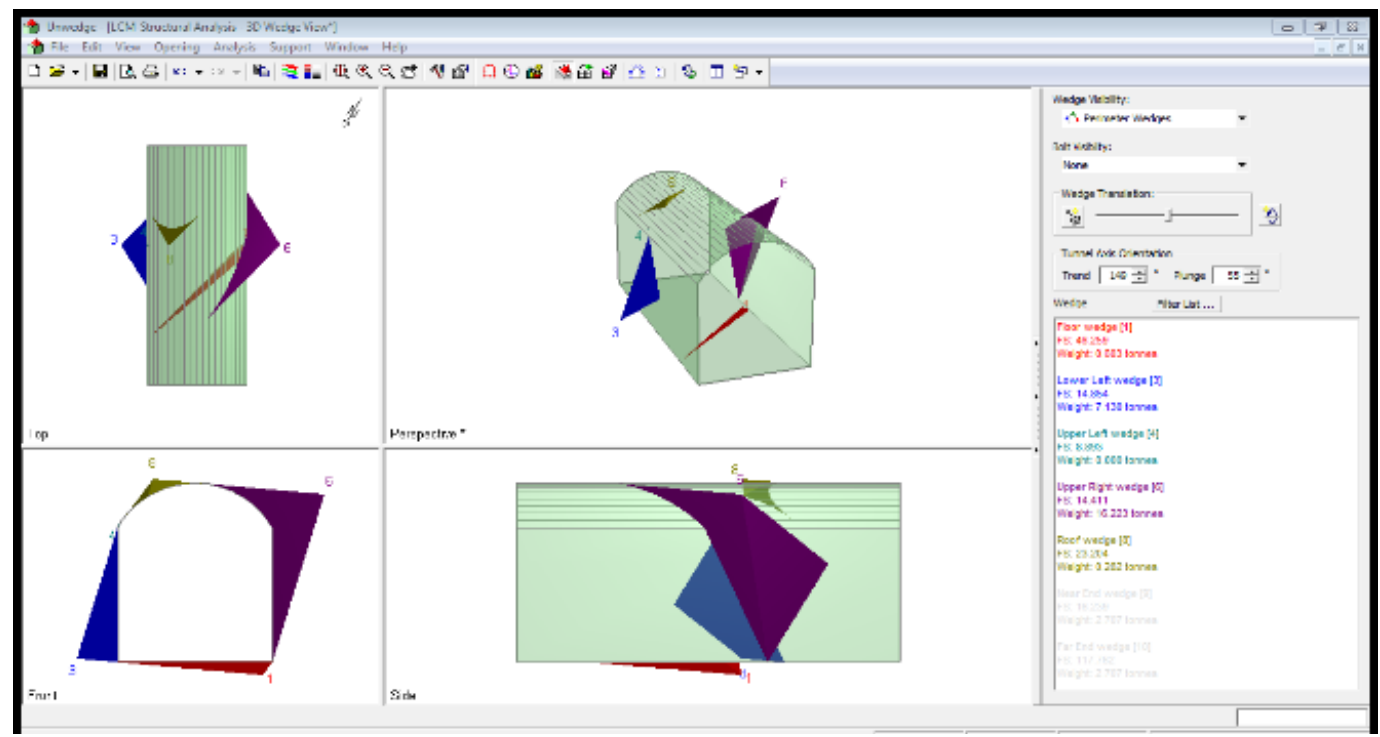

Figure 13: Unwedge commercial software analysis on the East Limb at Lubambe Mine

\subsection{Design Implications of Kinematic Feasibility}

The East Limb whose trend is $149^{\circ}$ in the N-S direction has structural controlled instability from the hanging wall side. These blocks may be a source of hanging wall dilution if not well controlled. On the other hand, maximum wedges of 155 tonnes are capable of forming within the orebody on the South Limb whose trend is $225^{\circ}$ in E-W direction as shown in Figure 14. For both situations, some form of rock bolting may be indicated, including wooden or bamboo dowels in ore if necessary to avoid tramp iron in the ore stream at the metallurgical plants. 


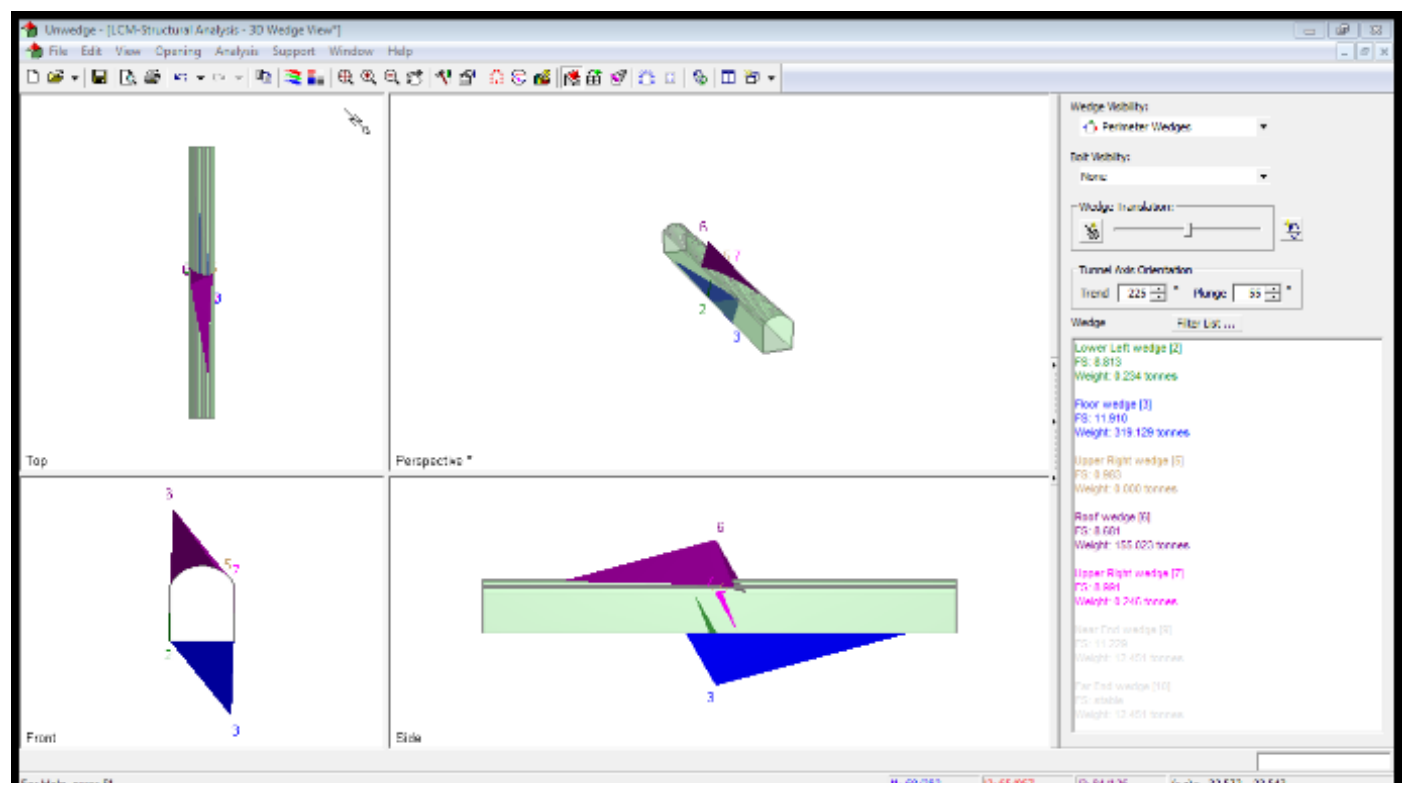

Figure 14: Unwedge analysis on the South Limb at Lubambe Mine

The tunnel orientation in this case becomes critical as can be seen from the structural analysis performed. It is evident that the trends of $149^{\circ}$ provide minimal wedges and therefore may require minimal support to contain. On the contrary, if not well managed, this trend may be a source of dilution. The trend of $225^{\circ}$ may present challenges when supporting due to the excessive size of wedges created, but has very minimal dilution during stoping in that the wedges are formed within the orebody envelope. Trend in tunnel development becomes critical as it may be favourable or not.

\subsection{Stope dilution assessment}

From observations at the Lubambe Mine, the analysis conducted actually confirmed why, historically, there had been high dilution rates recorded on the East Limb, compared to the South Limb at Lubambe, and why larger block fall out tend to be on the South Limb, compared to the East Limb.

\section{Conclusions}

The main objective of the study was to conduct UCS testing and underground discontinuity mapping at Lubambe in order to predict tunnel stability and stope dilution as well as support implications.

As a result of evaluating the variation in rockmass structure, it was possible to conclude that tunnel stability and stope dilution at Lubambe were influenced in the following manner:

- The East Limb in ore whose trend is $149^{\circ}$ in the north-south direction has structurally controlled instability on the waste hanging wall side resulting in the formation of 16 tonne fall out blocks of waste.

- The South Limb in ore whose trend is $225^{\circ}$ in the east - west direction has structurally controlled instability forming within the orebody with 155 tonne fall out wedges created.

- Establishment of major joint sets impacting on tunnel stability and overall stope stability led to the following conclusions:

- Based on discontinuity mapping conducted on already developed tunnels at Lubambe Copper Mine revealed an interaction of three prominent joints i.e J1(68/282), J2(65/057) and J3(84/126) respectively. This jointing system was identified to be controlling the overall stability of the tunnels.

- As a result of identifying the joint patterns sets $\mathrm{J} 1, \mathrm{~J} 2$ and $\mathrm{J} 3$ as the controlling factor it was possible to relate tunnel instability and dilution at Lubambe in both the East and South Limbs.

- Further, the analysis performed explained why there has been a higher rate of stope dilution from the hangingwall waste into the East ore Limb as compared to the South Limb at Lubambe Copper Mine

- Investigation of the variation of UCS on all rock units at Lubambe Copper Mine showed that:

- On the Ore shale 1 (OS1), a variation of strength results was obtained ranging from 5.80 MPa to 60.1 MPa with 26.7 MPa being the mean value.

$\circ$ On the OS2 the strength values obtained ranged from $13.2 \mathrm{MPa}$ to $91.6 \mathrm{MPa}$ with $36.2 \mathrm{MPa}$ being the mean value.

○ On Conglomerate, the strength values obtained varied from 8.6 MPa to 94.7 MPa with 46.09 MPa being the mean value. 
○ On the Arkose which forms the main footwall and hosts all primary developments varied from $15.3 \mathrm{MPa}$ to 105.3 MPa with 55.6 MPa being the mean value.

- A multi-point support design approach was suggested, whereby three designs (optimistic, normal and pessimistic) would be done based on one standard deviation below mean UCS, mean UCS, one standard deviation above mean UCS. The extreme variations in UCS indicate that in certain high stress environments, weaker strata of the same lithology may experience strength related failures, as observed in the mine at some places.

\section{Acknowledgements}

The authors wish to acknowledge the contributions of the Management of Lubambe Copper Mines ltd in resources and personnel, as well as the permission to share their data and ideas with the wider mining community. Thanks also go to Copperbelt University Schools of Graduate Studies and Mines \& Mineral Sciences. Not least, special thanks go to the employees of Lubambe for their hard work both underground and on surface.

\section{References}

[1] Hoek, E., Carranzo-Torres, C.T., and Corkum. B. 2002. Hoek-Brown Failure Criterion. Proc. North American Rock Mechanics Society meeting, Toronto.

[2] Harrison, J.P., and Hudson, J.A. 1997. Engineering Rock Mechanics Part 2: Illustrative worked examples. Imperial College of Science Technology and Medicine, University of London, UK pp 32 - 43.

[3] Harrison, J.P., and Hudson, J.A. 2000. Engineering Rock Mechanics. An introduction from the Principle, Imperial College of Science, Technology and Medicine, Pergamon press, University of London, UK, pp 138 - 143

[4] Hoek, E., and Diederichs, M.S. 2006. Empirical estimation of Rockmass Modulus. International Journal of Rock Mechanics and Mining Sciences, pp 43, 203 - 215.

[5] Bieniawski, Z.T. 1989. Engineering rock mass classification, New York, Wiley.

[6] Barton, N., Lien, R., and Lunde, J. 1974. Engineering Classification of Rock masses for the design of Tunnels Support, Rock Mechanics and Rock Engineering, Vol 6, pp 189-236.

[7] Serafim, J.L., and Pereira J.P. 1983. Consideration of the geomechanics classification of Bieniawski. Proc. Int. Symp. on Engineering geology and underground Construction, pp. 1133-1144.

Kalume H. "Uniaxial Compressive Strength Variation for Multi-point Support Design and Discontinuity Mapping for Tunnel Stability Analyses and Stope Dilution Assessment ." IOSR Journal of Applied Geology and Geophysics (IOSR-JAGG) 5.4 (2017): 53-62. 